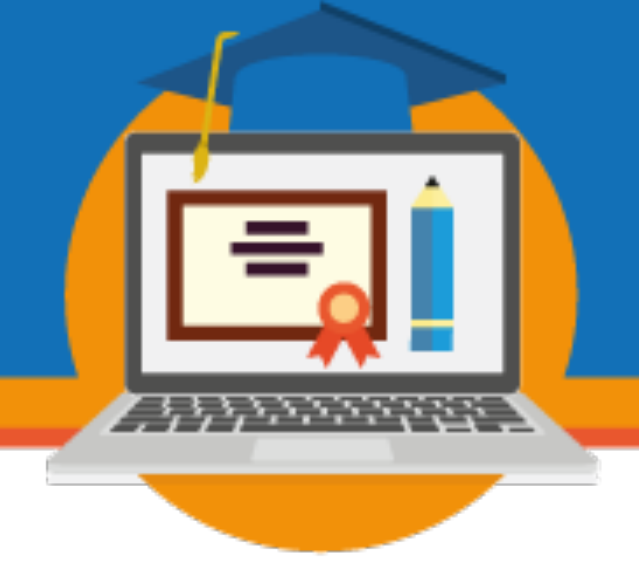

\title{
CONCEITOS E FATORES DE EVASÃO NA EDUCAÇÃO SUPERIOR: UMA ANÁLISE ENTRE AS MODALIDADES PRESENCIAL E A DISTÂNCIA
}

\author{
Amanda Catherine Pereira Bezerra ${ }^{1}$ - UnB \\ mandacatherine2@gmail.com \\ Giovanna de Oliveira Santana'-UnB \\ giovannaosantanna@gmail.com \\ Catarina de Almeida Santos ${ }^{3}-$ UnB \\ cdealmeidasantos@gmail.com
}

Eixo 02: Avaliação na EaD

\begin{abstract}
Resumo: O presente trabalho tem como objetivo apresentar resultados preliminares da pesquisa "EVASÃO NA UNIVERSIDADE DE BRASILIA: estudos sobre o perfil dos evadidos e fatores interferentes", que está sendo desenvolvida por duas estudantes de iniciação científica e faz parte da pesquisa as políticas de educação superior no Brasil, com destaque para a evasão na UnB. Para o desenvolvimento do trabalho estão sendo analisadas teses, dissertações e monografias, resultantes de pesquisas realizadas por estudantes da Universidade de Brasília, sobre a temática da evasão, nos cursos presenciais. No que se refere a evasão nos cursos a distância, foram analisados artigos publicados em periódicos que analisam os processos de evasão em diferentes universidades brasileiras. Os resultados preliminares apontam que há aspectos ou fatores específicos que levam a evasão, mas que também existem elementos comuns.
\end{abstract}

Palavras-chave: Evasão; Educação a distância; Educação Presencial.

\section{Introdução}

A educação no Brasil, sobretudo à educação superior, historicamente esteve no campo dos privilégios e não do direito. O país negou por anos o acesso da sua população a educação,

\footnotetext{
${ }^{1}$ Acadêmica do Curso de Pedagogia da Faculdade de Educação da Universidade de Brasília

${ }^{2}$ Acadêmica do Curso de Pedagogia da Faculdade de Educação da Universidade de Brasília

${ }^{3}$ Professora da Faculdade de Educação da Universidade de Brasília
}

III SEMINÁRIO DE EDUCAÇÃO A DISTÂNCIA 
no plano legal e operacional, tendo em vista que na maioria das vezes a nossa legislação foi omissa em relação a questão, e nas outras o que era aprovado não saia do papel.

A Constituição de 1988 é sem dúvida um marco na história do país, no campo dos direitos sociais em geral e dentre eles o direito a educação. Foi só nessa Constituição, celebrada como cidadã, que a educação é definida como direitos de todos, inclusive dos que a ela não tiveram acesso na idade obrigatória. Segundo o art. 205, sendo a educação um direito, cabem ao Estado e família o dever de assegurá-lo, devendo ser promovida e incentivada com a colaboração da sociedade.

O art. 208, por sua vez, definiu que o dever do Estado com a educação se efetivará mediante a garantia não só da educação básica, mas também como o acesso aos níveis mais elevados do ensino, da pesquisa e da criação artística, segundo a capacidade de cada um. Ao definir os princípios que devem nortear ou basear os processos educativos, o art. 206, definiu como o primeiro deles a igualdade de condições para o acesso e permanência.

Nesse sentido, analisar os processos de evasão, assim como suas variáveis, é fundamental para combate-lo, pois, garantir a permanência dos estudantes nos sistemas educativos, assim como a conclusão dos processos formativos, é não só princípio da educação nacional, como parte fundante da garantia do direito a educação.

Combater a evasão, no entanto, pressupõe compreender o seu conceito, assim como suas causas variáveis. Assim, o presente trabalho tem como objetivo apresentar os principais conceitos de evasão na educação superior, na literatura estudada, assim como compreender se existem e quais são as especificidades nas modalidades presencial e a distância.

Para o desenvolvimento do trabalho foram analisadas teses, dissertações e monografias, resultantes de pesquisas realizadas por estudantes da Universidade de Brasília, sobre a temática da evasão, nos cursos presenciais. No que se refere a evasão nos cursos a distância, foram analisados artigos publicados em periódicos que analisam os processos de evasão em diferentes universidades brasileiras. 


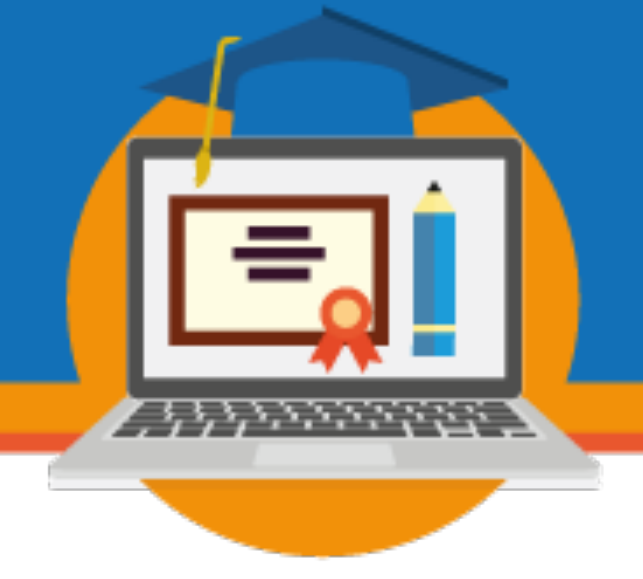

\section{Evasão na educação superior: a complexidade de um conceito}

A evasão na educação e, sobretudo na educação superior, é um fenómeno mundial, que apresenta diferentes motivos, alguns nem sempre identificados, pois careceria de pesquisa com todos ou maioria dos evadidos. Mas se a definição e ou identifica das causas ou fatores da evasão são complexas, definir o que é a evasão também não é uma tarefa fácil e muito menos possui um conceito único e consensual entre os pesquisadores da área.

Para autores como Palharini (2010), define a evasão como a saída definitiva do aluno do curso de origem sem concluí-lo, o que se dá por meio da não matricula e abandona do curso, por parte do aluno; quando o aluno comunica sua desistência oficialmente; quando se transfere para outro curso da instituição; quando o aluno é excluído pelas normas e regras institucionais; e ainda, quando se transfere para o mesmo curso em outra instituição.

Mas há atores como Ristoff que discorda no todo ou em parte da perspectiva anterior e defende que a evasão só pode ser assim caracterizada, quando há abandono dos estudos. Para esses teóricos, quando um estudante apenas migra de um curso para outro sem sair do sistema educacional, ocorre uma mobilidade e não a evasão. Assim, ao debater o fenômeno da evasão é importante destacar alguns elementos fundamentais para o debate, pois é preciso se questionar que tipo de evasão está em debate: evasão de curso, da instituição ou do sistema de ensino superior.

A complexidade do fenômeno é tal, que outras diferenciações estão em debate, como por exemplo a posição de Bueno (1993), que ao debater o tema separa evasão e exclusão acadêmica. Bueno compreende que a evasão corresponde a uma postura ativa do aluno que decide sair do curso, por razões próprias, mas quando essa saída se dá por responsabilidade da instituição de ensino e de tudo que a cerca, o fenômeno é outro e se chama de exclusão.

Evasão na educação superior presencial: o que dizem os trabalhos acadêmicos da Universidade de Brasília 


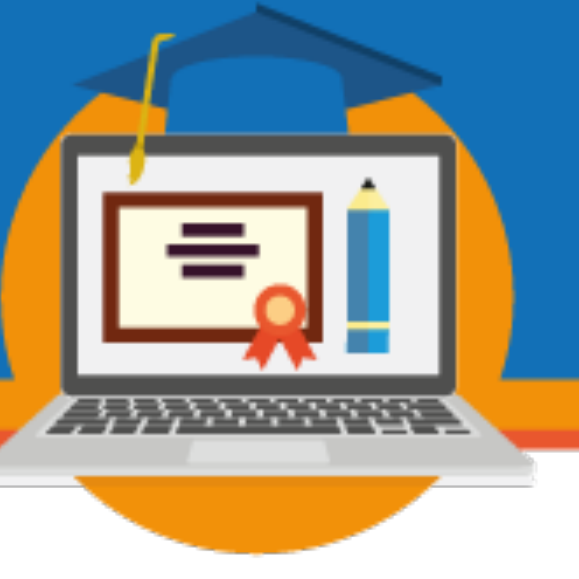

Os trabalhos aqui analisados foram produzidos por estudantes e pesquisadores da Universidade de Brasília, sobre o tema da evasão nos cursos presenciais, analisam o fenômeno em diferentes cursos da instituição, assim como suas principais causas. Lopes (2015) analisou esse processo no curso de Ciências Contábeis e apontou dois fatores preponderantes: conciliação entre trabalho e estudo como sendo o mais relevante, mas também aponta que as questões emocionais, motivacionais e financeiras dos alunos vêm contribuindo sobremaneira para que os estudantes evadam.

Uma outra pesquisa realizada sobre a evasão no mesmo curso, ou seja, Ciências Contábeis, foi feita por Amannda Cristina Meireles, no anão de 2017 com o título de "Evasão universitária: uma análise dos discentes do curso de graduação em Ciências Contábeis da Universidade de Brasília”. Nesse trabalho a autora aponta que a evasão da universidade, tem forte ligação com o perfil do estudante, sendo ligadas à fatores internos e externos.

Segundo Meireles (2017) os fatores internos considerados no trabalho e que contribuem para evasão consistem na infraestrutura da faculdade, corpo docente (o preparo para lidar com diferentes realidades), a falta de monitorias qualificadas para alunos que apresentam dificuldades pois tiveram o ensino básico fraco e assistência aos alunos de baixa renda. Já os externos apontados pela autora são a falta de orientação para a escolha do curso e acabam escolhendo apenas o "mais fácil", baixa concorrência no vestibular, problemas pessoais e distância entre a moradia e a universidade.

Conclusões similares chega a pesquisadora Amanda Alcebíades de Lima, ao analisar a evasão dos alunos dos cursos de Biblioteconomia, Museologia e Ciências da Computação, da Universidade de Brasília. Para Lima (2016) fatores como identificação com o curso, questões financeiras e perfil dos estudantes foram as principais causas da evasão dos citados cursos e da $\mathrm{UnB}$.

Outros trabalhos apontam os mesmos fatores já citados o que demonstra que precisamos nos debruçar sobre essas questões e buscar soluções que evitem a evasão e garantam a permanência e conclusão dos cursos, para quem já passou por um enorme funil que é conseguir uma vaga em um curso superior de uma IES pública. Se pensarmos que a UnB, para além de 
ser uma instituição visada por candidatos ao ensino superior em todo país, é a única universidade pública do Distrito Federal, que atende muitos alunos do entorno, é urgente desenvolver políticas de permanência para os seus estudantes, evitando assim o fenômeno da evasão. O quadro 1 traz uma síntese dos fatores internos e externos que contribuem para evasão.

\section{Quadro 1- Fatores de evasão dos cursos presenciais}

\begin{tabular}{|l|l|}
\hline \multicolumn{1}{|c|}{ Internos } & \multicolumn{1}{c|}{ Externos } \\
\hline Infraestrutura; & Distância entre a moradia e a faculdade; \\
Preparo do corpo docente; & Locomoção; \\
Conhecimentos trazidos do ensino básico; & Conciliação com o trabalho; \\
Assistência aos alunos de baixa renda; & Questões emocionais e motivacionais; \\
Falta de monitorias para auxílio dos alunos & Falta de orientação para a escolha do curso; \\
& Questões pessoais e financeiras \\
\hline
\end{tabular}

Os problemas internos das universidades se tornam um dos motivos para o grande número da evasão dos alunos, sendo eles a falta de preparo de alguns docentes que não possuem metodologias adequada para contemplar alunos de diferentes realidades, com níveis diferentes de formação no nível básico.

Muitas vezes o planejamento do curso e a oferta de disciplinas não levam em conta a realidade dos estudantes trabalhadores, e estão adequados aos alunos que podem se dedicar apenas aos estudos. Por isso, para evitar a evasão é fundamental planejar a oferta levando em consideração que muitos estudantes possuem grandes dificuldades e situações financeiras que não permitem passar o dia na universidade, moram em localidades distantes e não conseguem financiar passagens de ônibus ou alimentação.

Investir na expansão de programas de assistência estudantil para estes estudantes é muito importante, assim como na formação e conscientização de professores, coordenadores de cursos, diretores e chefes de departamento, além dos gestores das universidades e sistemas é essencial.

\section{SEMINÁRIO DE EDUCAÇÃO A DISTÂNCIA}


Não menos importante são os fatores externos que precisam ser considerados e debatidos para encontrar soluções. Via de regra esses fatores impactam na permanência dos estudantes, mas também na qualidade da formação. Aspectos como transporte, questões de saúde e conciliar estudo e trabalho levam muitos estudantes a desistirem do curso ou da universidade no geral.

\section{Evasão na educação superior a distância}

A evasão em cursos a distância costuma ser mais elevada que nos cursos presenciais e os estudos costumam apontar um conjunto de fatores e ou motivos para ocorrência do fenômeno. Apesar de apresentar muitos elementos em comum com a evasão nos cursos presenciais, as motivações ou causas da evasão, nessa modalidade, apresenta especificidades.

O quadro a seguir apresenta questões referentes ao educador/professor, às tecnologias, a modalidade e aos estudantes.

\section{Quadro 2- Fatores que influenciam na evasão na EaD}

\begin{tabular}{|l|l|l|l|}
\hline Educador & Tecnologias & EAD & Estudantes \\
\hline Perfil; & Pouco domínio; & Falta da atenção da & Questões sociais; \\
Pouco domínio; & Participação; & faculdade e do & Controle do tempo; \\
Ausência da figura & Falta de instrução; & administrativo; & Falta de acesso; \\
física & Erros virtuais & Metodologias; & Dificuldade para \\
& & Não alcance das & participar de atividades \\
& expectativas; & presenciais; \\
& & Processo solitário & Pouca autonomia; \\
& & & $\begin{array}{l}\text { Educação básica abaixo } \\
\text { das expectativas do curso }\end{array}$ \\
\hline
\end{tabular}

O aluno que opta por fazer o curso a distância, quase sempre encontra dificuldades para concluí-lo, por diferentes motivos. É comum que ao ingressar em um curso superior o estudante 
entre com muitas expectativas, que nem sempre ou na maioria das vezes, não são supridas ao longo do curso. Estudos apontam que esse é um dos grandes motivos para a desistência, e que essas expectativas não são contempladas em vários fatores que são decisivos no andamento do curso, na permanência do estudante e do projeto de educação a distância.

Em algumas instituições o corpo docente não está preparado para essa modalidade, fazendo com que muitos deles tragam para o curso a distância as metodologias realizadas nas aulas presenciais, não contemplando assim as expectativas do público alvo. A metodologia é um grande desafio para os professores, sobretudo nos cursos a distância, pois eles precisam instigar os alunos sem a presença física, o que significa que os conteúdos planejados, as formas de interação e toda condução do curso precisa ser muito bem pensadas e executadas.

As tecnologias fazem parte do nosso cotidiano e pode-se afirmar que vivemos em uma sociedade tecnológica. No entanto, isso não significa que todos saibam fazer o uso, sobretudo pedagógico delas e usá-las para fins educativos pode se tornar um grande desafio. Como a EaD, apesar das muitas possiblidades usam majoritariamente as tecnologias mais modernas, muitas vezes o estudante que opta por fazer um curso na modalidade $\mathrm{EaD}$, encontra muitas dificuldades de acesso e uso dos ambientes virtuais de aprendizagem.

Muitas estudantes optam pela modalidade por dificuldade do acesso ao ensino presencial onde na sua localidade, mas nem sempre tem a estrutura necessária para acompanhar o curso, nessa modalidade, seja de recursos tecnológicos ou humanos que ofereça o suporte que ele precisa. A pouca orientação, a baixa escolaridade, a pouca familiaridade com as tecnologias, entre outros aspectos dificulta o uso o processo educativo, além dos problemas e erros que as instituições cometem ao longo do processo.

Os estudos apontam que muitas instituições que ofertam o curso nas duas modalidades (presencial e a Distância), dão mais atenção ao presencial, reproduzindo, inclusive, as metodologias utilizadas no presencial e não buscam inovações para a melhoria do processo de ensino e aprendizagem. 
Um outro fator essencial para evasão é a questão cultural, tendo em vista que no processo de estudo a distância o sujeito precisa ser mais autônomo, ter mais disciplina e estratégias para organizar seus estudos e seu tempo. A figura do professor que exige leituras diárias e trabalhos constantes, não se faz tão presentes na $\mathrm{EaD}$, como na modalidade presencial. Um outro elemento que não pode ser ignorado é a baixa qualidade da educação básica que o cursista teve acesso, pois esse fator é muito importante nesse processo educativo mais solitário, sem a figura constante do professor e sem tutores mais presentes.

Apesar do curso ser a distância, existem as atividades presenciais e os estudos apontam que muitos estudantes encontram dificuldades para ir aos polos de apoio presencial realizar encontros e provas presenciais. As dificuldades para formas de acesso, questões financeiras, ou seja, há problemas de ordem: socioeconômicos, trabalho, dentre outros.

\section{Comparativos}

Após analisarmos fatores que levam a evasão nas modalidades presencial e a distância podemos dizer que há semelhanças das dificuldades encontradas para a conclusão do curso, mas também tem fatores que são específicas de cada modalidade, como pode ser observado no quadro 3.

\section{Quadro 3- Fatores de evasão em cursos presenciais e a distância: diferenças e similaridades}

\begin{tabular}{|l|l|}
\hline \multicolumn{1}{|c|}{ EaD } & \multicolumn{1}{c|}{ Presencial } \\
\hline Preparo do corpo docente & Preparo do corpo docente \\
\hline $\begin{array}{l}\text { Falta de metodologias que contemplam } \\
\text { à todos }\end{array}$ & Falta de metodologias que contemplam à todos \\
\hline Questões socioeconômicas & Questões socioeconômicas \\
\hline Questões sociais & Questões sociais \\
\hline Falta de orientação para a escolha do & Falta de orientação para a escolha do curso \\
\hline
\end{tabular}




\begin{tabular}{|l|l|}
\hline curso & \\
\hline Déficit no ensino básico & Déficit no ensino básico \\
\hline Ausência da figura física & Locomoção \\
\hline Processo “solitário" & Distância da faculdade \\
\hline Problemas com o uso das TIC's & Auxílio \\
\hline $\begin{array}{l}\text { Dificuldades para participar das } \\
\text { atividades }\end{array}$ & Tempo para trabalho \\
\hline Preconceito com o método de ensino & Infraestrutura \\
\hline
\end{tabular}

\section{Considerações finais}

A evasão na educação superior apresenta conceitos nem sempre consensuais, mas com alguns elementos em comum. No entanto, independentes das diferenças conceituais, esse fenômeno é uma realidade nas modalidades presenciais e a distância. Além disso, apresenta especificidades e semelhanças, como foi demonstrado no decorrer d texto. Na educação a distância, trabalhos como o de Anderson Santos (2014) apontam que a evasão dos cursos à distância está ligada a fatores relacionados a características individuais dos alunos e falta de incentivo da instituição. Dentre os problemas ligados a instituição os mais relatados como causa do abandono dos discentes, são apoio insuficiente ao aluno e insatisfação destes com o desempenho dos tutores.

Mas há fatores ligados também as características do aluno, como indisciplina, problemas familiares, falta de tempo e dificuldades em fazer uso das ferramentas eletrônicas. Não por acaso, Santos aponta que a falta ou o baixo domínio da tecnologia é apontado como a maior dificuldade no ingresso de um curso a distância pelos estudantes, com $60 \%$.

Quando olhamos as razões para a evasão nos cursos presenciais, os trabalhos apresentaram fatores relacionados as questões econômicas, mas também pedagógicas. Quando 


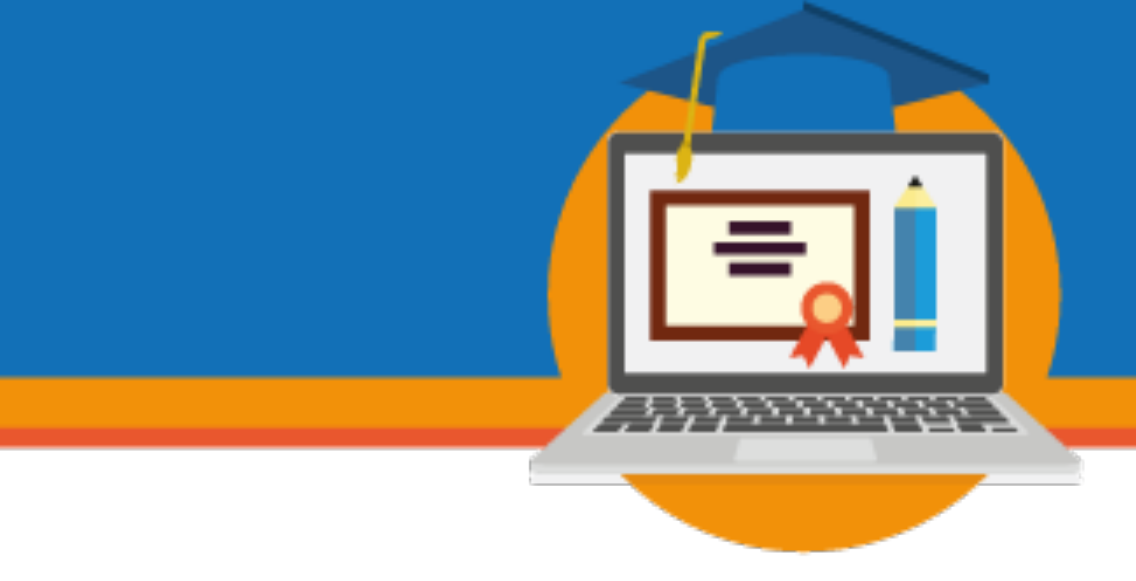

comparamos as duas modalidades, além de terem em comum as questões socioeconômicas e falta de prepara dos discentes, as pesquisas apontaram déficit no ensino básico e falta de orientação na escolha do curso, são questões atinentes as duas modalidades.

\section{Referências}

BUENO, J. L. A Evasão de Alunos. Jornal da USP, São Paulo, USP, 14 a 20 de junho de 1993.

PALHARINI, F. A. Evasão, exclusão e gestão acadêmica na UFF: passado, presente e futuro. Cadernos do ICHF: Série Estudos e Pesquisas. Universidade Federal Fluminense - Instituto de Ciências Humanas e Filosóficas. Niterói, 2010.

RISTOFF, D. Evasão: Exclusão ou Mobilidade. Santa Catarinha, UFSC, 1995 (MIMEO)

SANTOS, Anderson George Rafael. A evasão nos cursos de graduação a distância UAB/Unimontes no polo de São João da Ponte/MG. Revista Multitexto, 2013, v. 2, n. 01. Disponível em: http://www.ead.unimontes.br/multitexto/index.php/rmcead/article/view/119. Acesso em: 15 de dezembro de 2019.

LOPES, Kelson dos Santos. Evasão no curso de ciências contábeis da UnB: uma análise das características e motivos dos alunos evadidos no período de $1^{\%} / 2011$ à 2\%/2013-. Trabalho de conclusão de Curso, UnB, 2015. Disponível em: < http://bdm.unb.br/handle/10483/13310>. Acesso em: 20 de agosto de 2019.

MEIRELES, Amannda Cristina. Evasão universitária: uma análise dos discentes do curso de graduação em Ciências Contábeis da Universidade de Brasília. Trabalho de Conclusão 


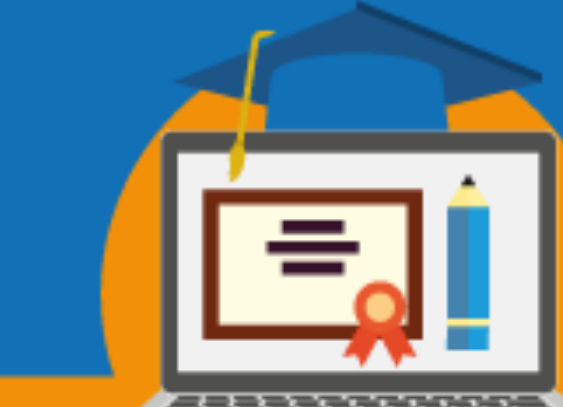

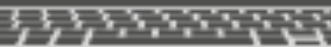

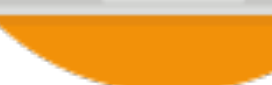

de Curso, UnB, 2017. Disponível em: < http://bdm.unb.br/handle/10483/18130>. Acesso em: dezembro de 2019.

LIMA, Amanda Alcebíades de. Evasão dos alunos de Biblioteconomia, Arquivologia e Museologia da Faculdade de Ciência da Informação da Universidade de Brasília. Trabalho de Conclusão de Curso, UnB, 2016. Disponível em: < http://bdm.unb.br/bitstream/10483/20170/1/2016 AmandaAlcebiadesdeLima tcc.pdf $>$.

Acesso em: Janeiro de 2020.

PACHECO, Andressa Sasaki Vasques; NAKAYAMA, Marina, Keiko; RISSI, Maurício. Evasão e Permanência dos estudantes de um curso de Administração a distância do sistema de universidade aberta do Brasil: uma teoria multiparadigmática. Revista de Ciências da Administração, $\quad$ v. $\quad 17, \quad \mathrm{n}^{\circ} \quad 41 . \quad$ Disponível em: https://periodicos.ufsc.br/index.php/adm/article/view/2175-8077.2015v17n41p65/pdf 52. Acesso em: 10 de janeiro de 2020.

Bentes, Márcia Cristina Benigno and Kato, Olívia Misae Fatores que afetam a evasão na educação a distância: curso de administração. Psicol. educ., Dez 2014, no.39, p.31-45. Disponível em: $\quad<$ http://pepsic.bvsalud.org/scielo.php?script=sci arttext\&pid=S141469752014000200004\&lng=pt\&nrm=iso $>$. Acesso em: 10 de janeiro de 2020. 


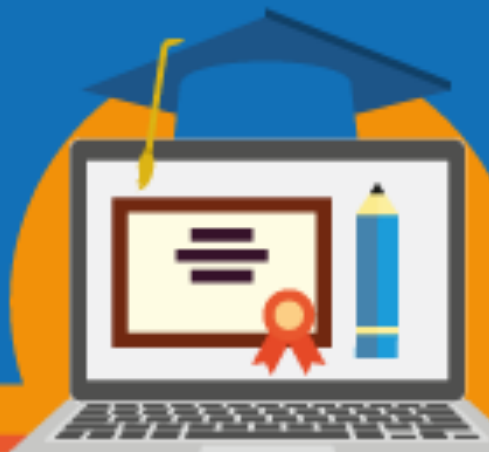

III SEMINÁRIO DE EDUCAÇÃO A DISTÂNCIA

Diálogos sobre EaD e uso das TDIC na educação: regulamentação em tempos recentes 3 a 6 de novembro de 2020 - Brasília/DF - Online 